\title{
Gastrointestinal involvement in COVID-19: a systematic review and meta-analysis
}

\author{
Theodore Rokkas
}

Henry Dunant Hospital, Athens Greece

Abstract

\section{Introduction}

At the end of 2019, a cohort of unidentified viral pneumonia cases was first reported in Wuhan, the capital city of Hubei Province in China [1]. Soon, the virus responsible was identified [2] and named SARS-CoV-2 (severe acute respiratory syndrome coronavirus 2) by the International Committee

Gastroenterology Clinic, Henry Dunant Hospital, Athens, Greece

Conflict of Interest: None

Correspondence to: Theodore Rokkas MD, PhD, FACG, AGAF, FEBGH, 192b Alexandras Ave., Athens 11521, Greece, e-mail: sakkor@ otenet.gr

Received 21 April 2020; accepted 5 May 2020; published online 6 June 2020

DOI: https://doi.org/10.20524/aog.2020.0506 on Taxonomy of Viruses. SARS-CoV-2 belongs to the betacoronavirus genus, which also includes the SARS-CoV and the Middle East Respiratory Syndrome Coronavirus (MERS-CoV), and is a single-stranded RNA virus that genetically strongly resembles the bat coronaviruses [3]. However, the intermediate reservoir has yet to be found $[3,4]$. Consequently, the disease caused by this novel virus was named COVID-19 (coronavirus disease 2019) by the World Health Organization [5]; it is the third coronavirus identified to cause severe lung disease in humans, like the other two previous coronaviruses, i.e., SARS$\mathrm{CoV}$ and MERS-CoV [5,6]. After Wuhan, SARS-CoV, because of its high infectivity due to nonexistent immunity in the community, rapidly spread to the rest of China and then the rest of the world, causing a major pandemic and undoubtedly an ongoing global health crisis.

Most COVID-19 patients typically present with fever and respiratory symptoms $[1,4,6]$. However, some patients also have gastrointestinal (GI) manifestations, such as diarrhea, nausea, 
vomiting and abdominal pain [4,6]; furthermore, in some COVID-19 patients SARS-CoV-2 RNA was identified in anal/ rectal swabs and stool specimens [7-10]. Interestingly, in some COVID-19 patients, SARS-CoV-2 RNA was detected in feces even after the clearance of the virus in the upper respiratory tract $[7,8,11]$. Moreover, former studies [12] have shown that SARS-CoV receptor ACE2 (angiotensin-converting enzyme 2 ) is expressed in small intestine epithelial cells. All the above suggest that SARS-CoV-2 can actively infect and replicate in the GI tract, with important implications for disease management, transmission and infection control. Therefore, reviews and critical evaluations of the rapidly evolving research evidence on this potentially lethal disease are vitally necessary. In this study we systematically reviewed and meta-analyzed the current evidence suggesting involvement of the digestive system in COVID -19 .

\section{Materials and methods}

\section{Study identification and extraction of data}

PubMed, MEDLINE and Embase database medical literature searches for human studies were performed up to the 20th of April 2020, using suitable keywords, i.e., (("COVID19”[All Fields] OR “COVID-2019”[All Fields] OR “severe acute respiratory syndrome coronavirus 2"[Supplementary Concept] OR "severe acute respiratory syndrome coronavirus 2"[All Fields] OR “2019-nCoV”[All Fields] OR "SARS-CoV-2"[All Fields] OR "2019nCoV”[All Fields] OR (("Wuhan"[All Fields] AND ("coronavirus"[MeSH Terms] OR “coronavirus”[All Fields])) AND (2019/12[PDAT] OR $2020[\mathrm{PDAT}]))$ ) OR ("severe acute respiratory syndrome coronavirus 2"[Supplementary Concept] OR "severe acute respiratory syndrome coronavirus 2"[All Fields] OR "sars cov 2"[All Fields])) AND GASTROINTESTINAL[All Fields] AND (MANIFESTATIONS[All Fields] OR INVOLVEMENT[All Fields] OR ("gastrointestinal tract"[MeSH Terms] OR ("gastrointestinal"[All Fields] AND "tract"[All Fields]) OR "gastrointestinal tract"[All Fields] OR ("gi"[All Fields] AND "tract"[All Fields]) OR "gi tract"[All Fields])). In addition, a manual search of all review articles, editorials and retrieved original studies was also performed. The meta-analysis was performed in accordance with PRISMA [13].

\section{Selection criteria}

Inclusion and exclusion criteria were defined prior to the literature search. Hence, the following criteria had to be met for studies to be included in this meta-analysis: 1) published as full articles or letters to the Editor; 2) written in English; and 3) cohort studies, with extractable data concerning the involvement of the digestive system in SARS-Cov-2 infection, including at least 15 patients. Exclusion criteria were the following: 1) studies not meeting the inclusion criteria; 2) studies without data for retrieval; 3) duplicate studies; and 4) the less informative publication of two on the same study. Concerning quality, the cohort studies included in this meta-analysis were assessed by using the NewcastleOttawa Quality Assessment Scale for cohort studies [14]. This scale assesses the main sources of bias, including the selection of study cohorts, comparability of cohorts, and outcome assessment. Furthermore, it uses a "star system" to judge a study on these three broad perspectives, with a maximum possible score of 9 . According to the score, and therefore the relevant risk of bias, studies were classified as low, fair, and high quality.

\section{Statistical analysis}

The statistical analyses used were described in detail in our previous publications $[15,16]$. Briefly, the individual and the pooled prevalence rates, with $95 \%$ confidence intervals (CI), were derived by employing the fixed-effects or the random-effects model, as appropriate $[17,18]$, and were depicted in constructed forest plots for visual display. Heterogeneity was measured with the Cochran Q test and the $I^{2}$ statistic $[19,20]$. In addition, we used cumulative meta-analysis to explore whether the calculated prevalence rates remained steady [19]. The Comprehensive Meta-Analysis software, version 2 (BIOSTAT INC., Englewood, NJ, USA) and Stata statistics (Stata 13.2, StataCorp, College Station, TX) were used throughout this meta-analysis.

\section{Sensitivity analyses and publication bias}

In case of significant heterogeneity, sensitivity analyses were employed to check the consistency of the results. Thus, to explore any significant influence of single studies on the pooled prevalence rates, we performed the exclusion method by repeating the meta-analysis after excluding single studies one at a time [19]. The possibility of publication bias was examined by constructing funnel plots $[21,22]$. Their symmetry was measured by Egger's regression test and the Begg and Mazumdar adjusted rank correlation test [23,24].

\section{Results}

\section{Descriptive assessment and characteristics of the studies}

A flowchart depicting the study selection is shown in Fig. 1. Of the 2256 titles initially found by the literature searches, 37 cohort studies were found suitable for meta-analysis [1,6,25-59]. There were 33 studies from China [1,25-52,55-57], 1 from South Korea [53], 1 from Singapore [54], and 2 from the USA $[58,59]$, including a total of 5601 patients. Thirtyfour studies $[1,6,25-54,58,59]$ reported data from adults and 3 studies [55-57] from children. The main characteristics of the 37 studies included in the meta-analysis are shown in Table 1. 


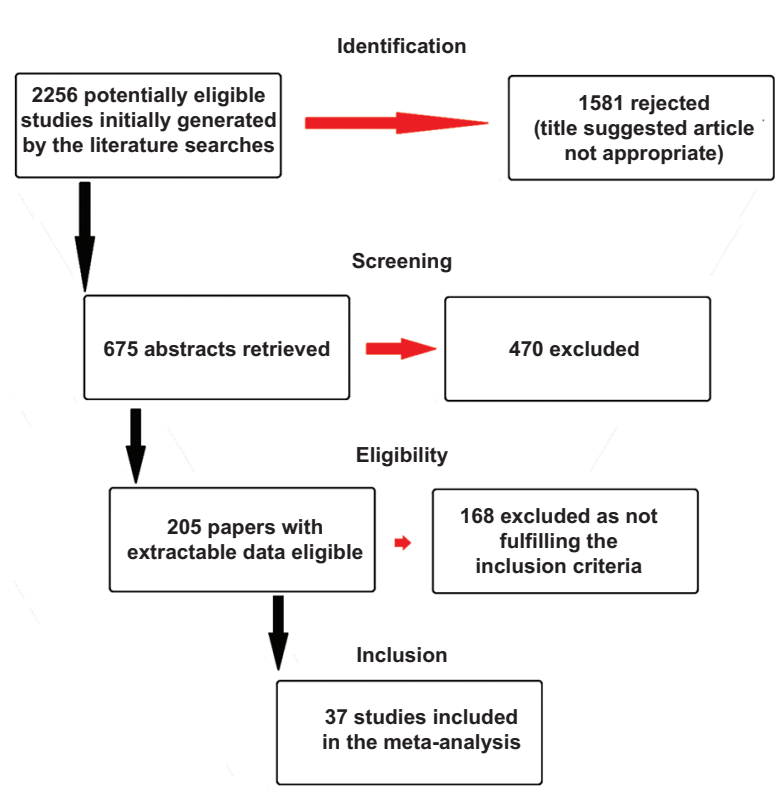

Figure 1 Flow diagram of the studies identified in this meta-analysis

According to the Newcastle-Ottawa Quality Assessment Scale, 5 studies (13.5\%) were classified as high quality, $10(27 \%)$ as fair, and $22(59.5 \%)$ as low quality.

\section{Prevalence rates of GI manifestations}

\section{a. All GI symptoms}

All 37 included studies [1,6,25-59] reported one or more GI symptom in their total of 5601 COVID-19 patients. The individual and pooled prevalence rates for all symptoms are shown in Fig. 2. Since there was significant heterogeneity in the included studies $\left[\mathrm{Q}=833.67, \mathrm{df}(\mathrm{Q})=36, I^{2}=95.68 \%, \mathrm{P}<0.001\right]$, a random-effects model was applied, which yielded a pooled prevalence rate of $9.8 \%$ (95\%CI 6.4-14.7) with a test for overall effect $\mathrm{Z}=-9.409, \mathrm{P}<0.001$. In addition, significant publication bias was found [asymmetry estimation $P$ (2-tailed) value 0.001 by Egger's regression test], as seen in the funnel plot (Fig. 3). Furthermore, sensitivity analyses were utilized to detect the presence of any biases related to the inclusion of different population studies. Thus, the exclusion of any study did not alter the summary results substantially (Fig. 4A). Similarly, the cumulative meta-analysis did not alter the results significantly (Fig. 4B).

\section{b. Diarrhea}

Thirty-five studies [1,25-45,47-59] reported diarrhea in their COVID-19 patients. The individual and pooled prevalence rates are shown in Fig. 5A. Since there was significant heterogeneity in the included studies $\left[\mathrm{Q}=329.15, \mathrm{df}(\mathrm{Q})=34, I^{2}=89.27 \%\right.$, $\mathrm{P}<0.001$ ], a random-effects model was applied, which yielded a pooled prevalence rate of $10.4 \%$ (95\%CI 7.7-13.9) with a test for overall effect $\mathrm{Z}=-12.87, \mathrm{P}<0.001$.

\section{c. Nausea/vomiting}

Twenty-two studies [25-31,34-36,39,40,46,49-52,55-59] reported nausea/vomiting in their COVID-19 patients. The individual and pooled prevalence rates for this symptom are shown in Fig. 5B. Similarly to diarrhea, there was significant heterogeneity in the included studies $[\mathrm{Q}=326.56, \mathrm{df}(\mathrm{Q})=21$, $\left.I^{2}=93.57 \%, \quad \mathrm{P}<0.001\right]$; therefore, a random-effects model was applied, which yielded a pooled prevalence rate of $7.7 \%(95 \%$ CI $4.8-12.1)$ with a test for overall effect $Z=-9.74$, $\mathrm{P}<0.001$.

\section{d. Abdominal discomfort/pain}

Seven studies [26,27,30,31,41,51,59] reported abdominal discomfort/pain in their COVID-19 patients. The individual and pooled prevalence rates for all symptoms are shown in Fig. 5C. Since there was significant heterogeneity in the included studies $\left[\mathrm{Q}=29.12, \mathrm{df}(\mathrm{Q})=6, I^{2}=79.45 \%, \mathrm{P}<0.001\right]$, a random-effects model was applied, which yielded a pooled prevalence rate of $6.9 \%$ (95\%CI 3.9-11.9) with a test for overall effect $\mathrm{Z}=-8.51, \mathrm{P}<0.001$.

\section{e. Fecal detection of SARS-COV-2 RNA}

Three studies $[26,30,43]$ reported fecal detection of SARSCoV-2 RNA in their COVID-19 patients. A total of 147 patients were included in these studies and in 52 viral RNA was detected in feces. Thus, the prevalence rate for SARSCoV-2 RNA positivity was $30.3 \%$ (95\%CI 10.5-61.6) as shown in Fig. 6A.

\section{Subgroup analyses}

In order to examine the influence of factors such as the patient's age, COVID-19 severity and geographic region on the results of this meta-analysis, we performed the respective subgroup analyses and the results are shown in detail in Table 2. Thus, the prevalence rate concerning symptoms was similar in adults and children. The prevalence rate $(95 \% \mathrm{CI})$ for all symptoms was $9.8 \%$ (6.414.7) in adults and 9.6\% (6.3-14.3) in children. Concerning disease severity, in patients with severe COVID-19 the prevalence of GI symptoms was $16.6 \%$ (6.6-35.9), higher than in patients with non-severe COVID-19, who showed a prevalence of $11.7 \%$ (4.1-29.1).

\section{Discussion}

The novel SARS-CoV-2, because of its high infectivity, is currently causing a major pandemic and undoubtedly constitutes a global health crisis. Consequently, in the short 3-month period (January to March) since December 2019, we 


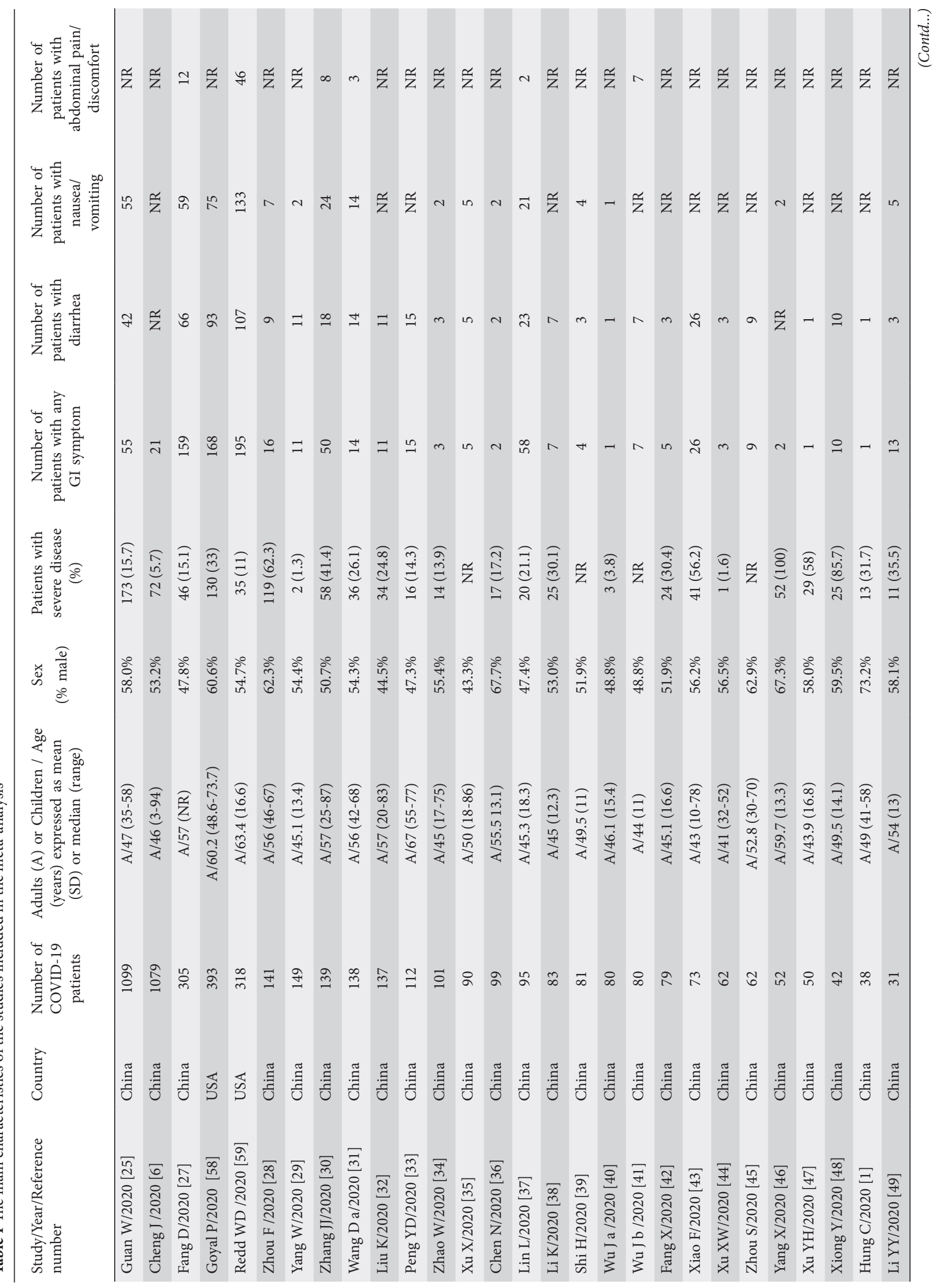




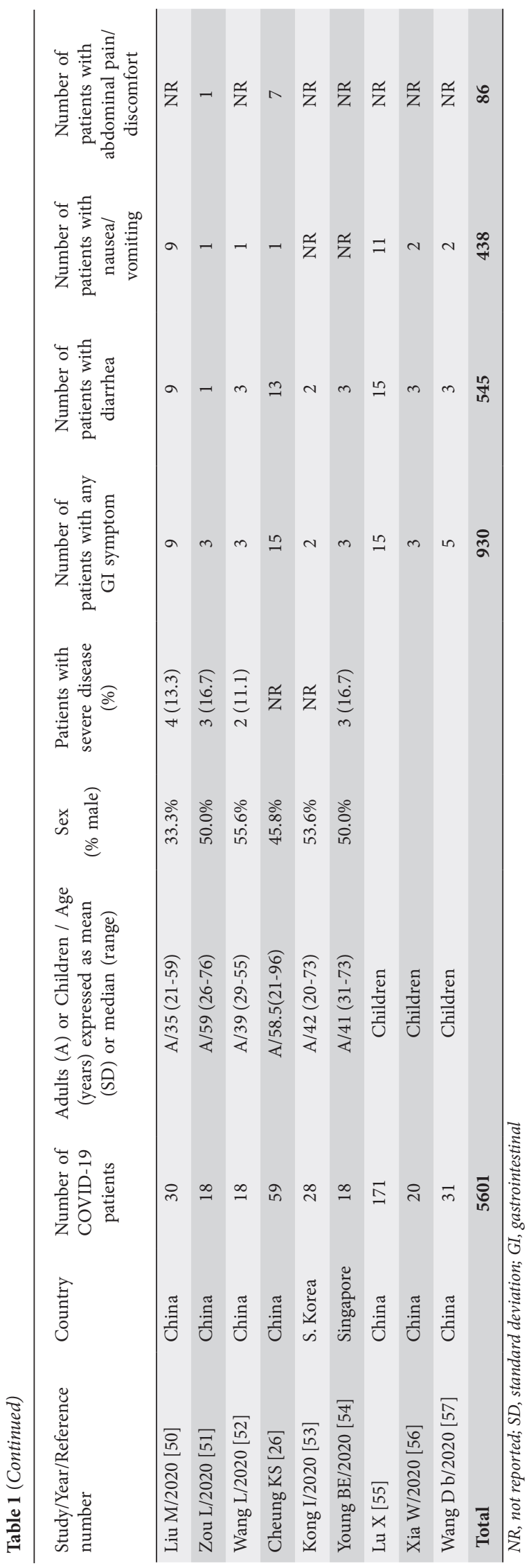

have been faced with an explosion of publications concerning COVID-19 cohorts of patients. COVID-19 patients commonly develop fever and respiratory illness. However, some patients also report GI symptoms such as diarrhea, vomiting and abdominal pain. This meta-analysis pooled current individual data concerning the involvement of the digestive system in COVID-19 and showed that a percentage of the COVID-19 patients will manifest GI symptoms. Thus, the pooled prevalence rate for all symptoms was $8.9 \%$, while the separate rates were $9.6 \%$ for diarrhea, $6.6 \%$ for nausea/vomiting and 5.8\% for abdominal discomfort/pain. In the subgroup analysis in adult patients these rates were $8.7 \%, 9.6 \%, 6.5 \%$ and $5.8 \%$, respectively. In children the pooled figures were $9 \%$ for all symptoms, $9 \%$ for diarrhea and $6.8 \%$ for nausea/vomiting. In addition, the prevalence of GI symptoms in patients with severe COVID-19 (16.6\%) was higher than in non-severe COVID-19 (11.7\%). Finally, in over $30 \%$ of patients SARS-CoV-2 RNA was detected in feces by reverse-transcriptase polymerase-chain-reaction (RT-PCR).

Concerning the quality of the included studies, $13.5 \%$ were classified as high, $27 \%$ as fair, and $59.5 \%$ as low quality. This is expected in meta-analyses of observational studies. While this meta-analysis was in preparation, an "ahead of print e-publication" cohort study, accompanied by meta-analysis, has emerged [26]. This study included almost exclusively Chinese data. At this point it must be stressed that in our meta-analysis, apart from Chinese data, we have included the first data coming from other countries (USA), with a reasonable number of patients [58,59], which differentiates the results. Overall, GI symptoms appeared to be more common in US rather than in Chinese patients. This difference remains to be confirmed by more studies and it could reflect geographic variation or differential reporting. In addition, in our meta-analysis the inclusion threshold was 15 patients whereas the above-mentioned publication included numerous studies even with one patient, which in meta-analysis methodology constitutes a severe limitation.

During the outbreak of SARS-CoV disease in 2003, among other symptoms, approximately $20 \%$ of the patients manifested GI symptoms [60,61]. GI symptoms were also noted in MERS-CoV disease [62], with cohorts reporting symptoms in $11.5-32 \%$ of the patients. Interestingly, there is evidence showing that coronaviruses show a tropism to the GI tract, which might explain the frequent occurrence of diarrhea in coronavirus infections. Thus, SARS-CoV RNA was detected readily in stool specimens of SARS patients [63], with active viral replications seen by electron microscopy on biopsy or autopsy specimens of small and large intestines [61]. Similarly, it has been shown that MERS-CoV often resulted in enteric infection, with human intestinal epithelial cells being highly susceptible to MERS-CoV [64]. Moreover, sustainable vigorous viral replication was noted. It seems, therefore, that GI tropism could be behind the occurrence of diarrhea in all SARS-CoV infections. Consequently, the SARS$\mathrm{CoV}$ fecal route could lead to virus transmission (Fig. 6B), especially when infective aerosols from the toilet plume 


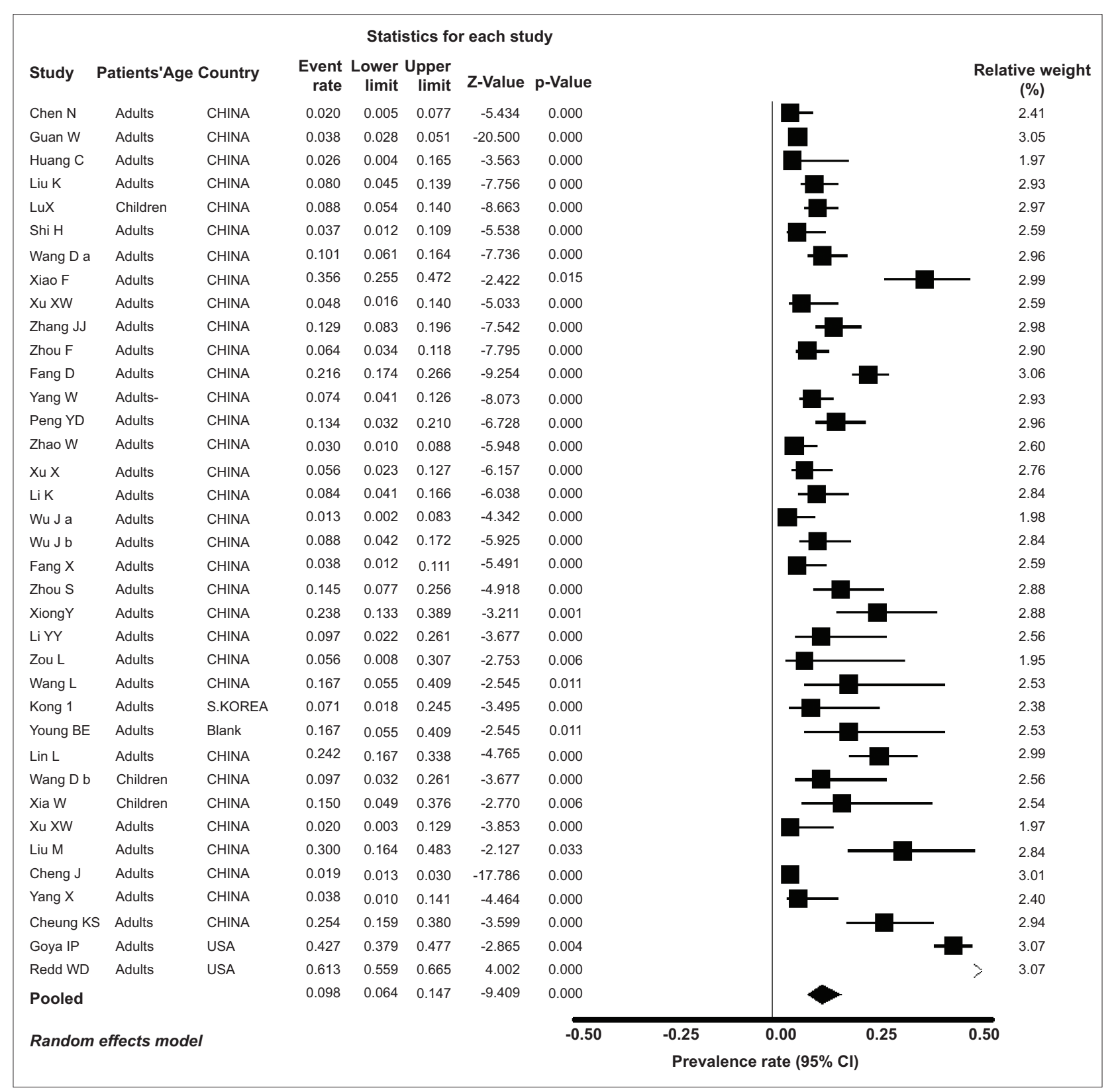

Figure 2 Forest plot showing individual and pooled prevalence ratios and $95 \%$ confidence intervals (CIs)

are generated [65]. Since there is approximately an $80 \%$ genome sequence identity between the novel SARS-CoV-2 and SARS-CoV $[3,67]$, GI infection by SARS-CoV-2 is not surprising. Interestingly, this meta-analysis showed that the prevalence of GI symptoms was higher in patients with severe disease in comparison to those with less severe disease. This finding might convey potential prognostic implications, as COVID-19 patients who manifest GI symptoms may require closer monitoring.

The mechanism related to GI tract involvement in SARSCoV-2 infection could be explained by the mediation of ACE2 cell receptors. Indeed, previous studies concerning SARS$\mathrm{CoV}$ have shown that both viral glycoproteins, i.e., encoding and expressing the spike (S), could bind to the entry cellular receptor ACE2 (Fig. 6C), thus entering human cells [2, 3,66 ]. In addition, it has been shown that the receptor-binding domain on SARS-CoV-2 could bind to human ACE2 with high affinity $[67,68]$. While ACE2 is expressed in abundance in the alveolar cells in the lungs, the receptor is also highly expressed in the GI tract, especially in the small (Fig. 6D) and large intestines $[12,69]$. These data provide valuable insight into the receptor-mediated entry into the host enteric cells, and furthermore provide a basis for its possible transmission route through the feces.

According to this meta-analysis, in 30.3\% (95\%CI 10.5$61.6 \%)$ of the patients SARS-CoV-2 RNA was detected in feces. Interestingly there are reports on asymptomatic patients positive for SARS-CoV-2 RNA by RT-PCR in 
a stool specimen, even 17 days after the viral diagnosis [11]. Furthermore, in this report, the positivity in feces remained for 9 additional days, even when the respiratory tract specimens were negative by RT-PCR. All the above suggest that viral shedding from the GI tract may be abundant and may last long after resolution of clinical symptoms. In agreement with this finding are data from previous SARS-CoV studies, which showed that viral
RNA was detected after 30 days in stools of SARS patients [70]. However, despite the similarities, it must be stressed that the viral dynamic of SARS-CoV-2 in the GI tract is not well known so far and might not follow that of SARS$\mathrm{CoV}$ as observed in the respiratory tract $[51,71,72]$.

The direct impact of this meta-analysis data refers to the infectivity of the disease. Towards this notion, a recent study showed that SARS-CoV-2 could remain viable in aerosols for

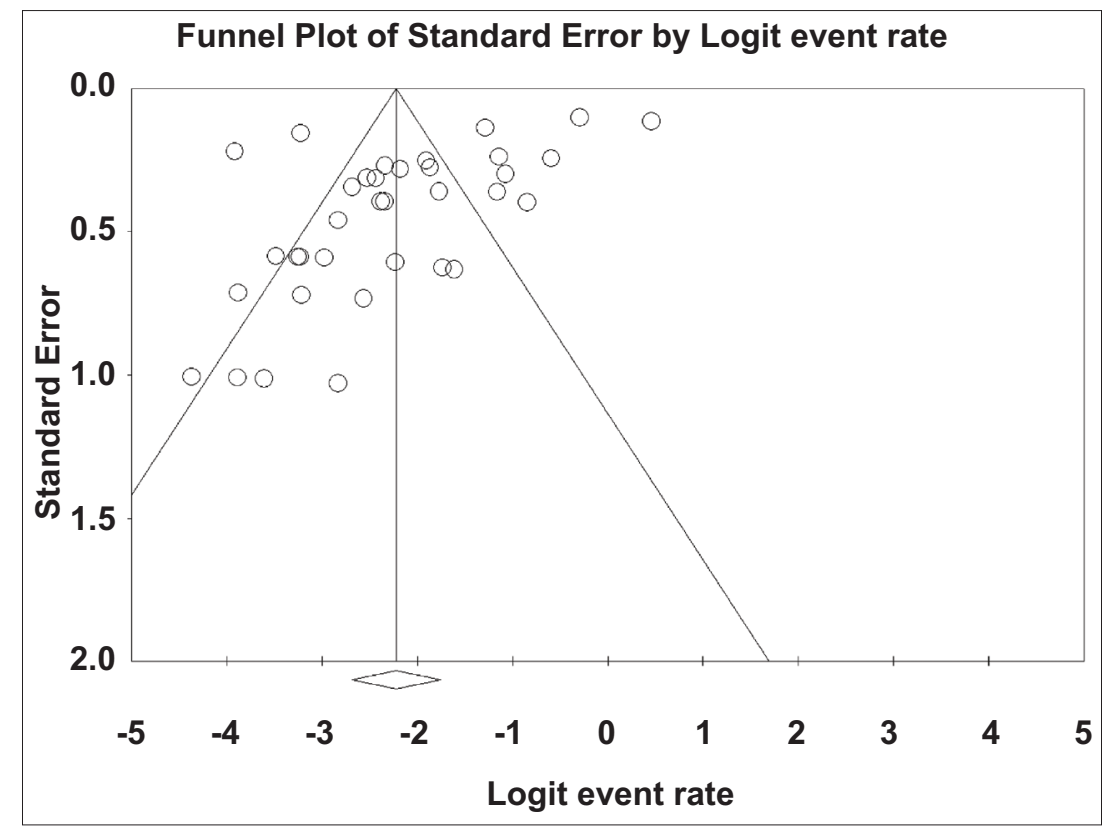

Figure 3 Funnel plot of all studies included in the meta-analysis. There is evidence of publication bias $(\mathrm{P}=0.001$ by regression test $)$

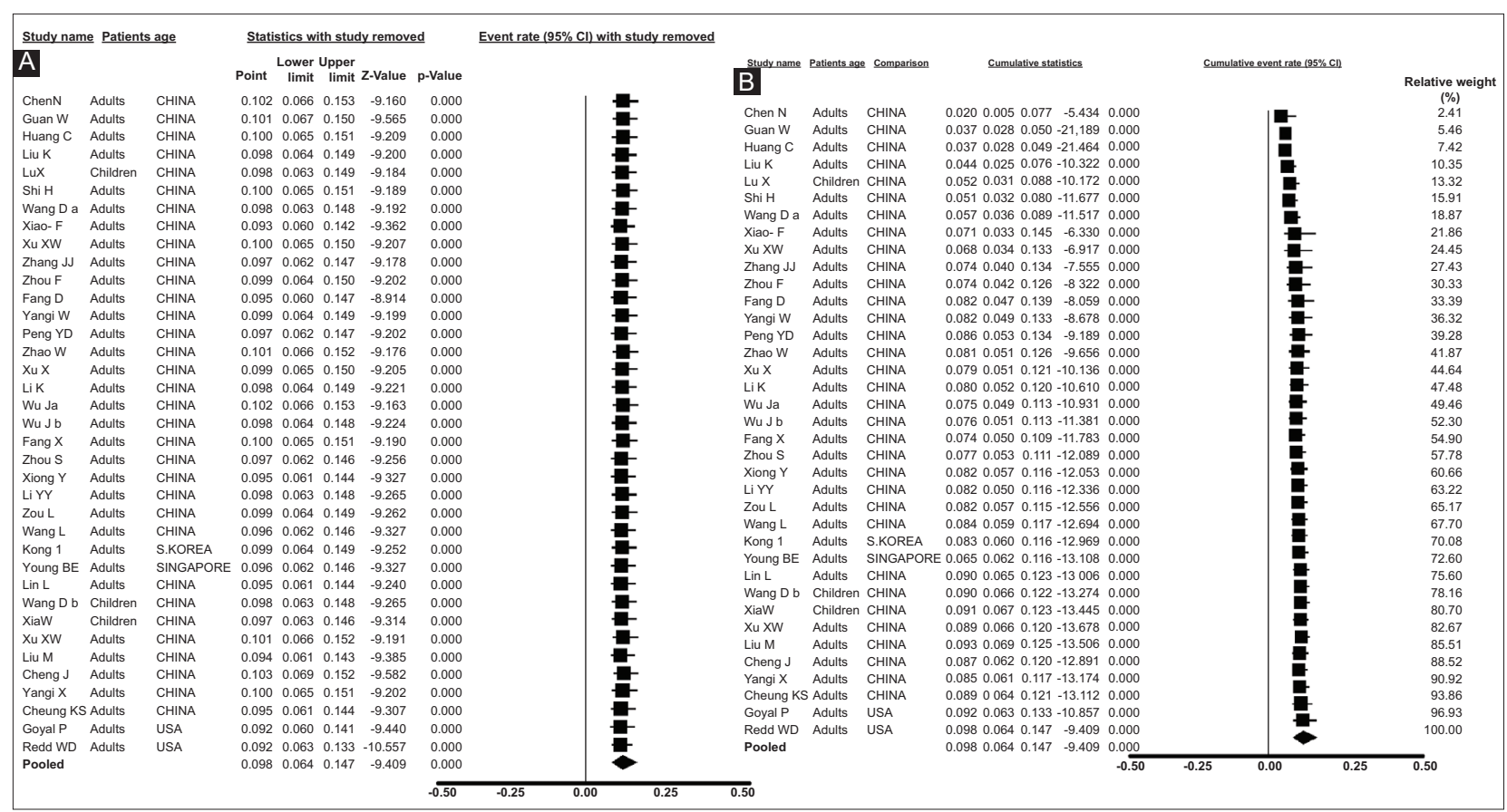

Figure 4 (A) Exclusion sensitivity plot showing the effect of exclusion of any study on the magnitude of the summary estimate. (B) Cumulative meta-analysis of included studies 


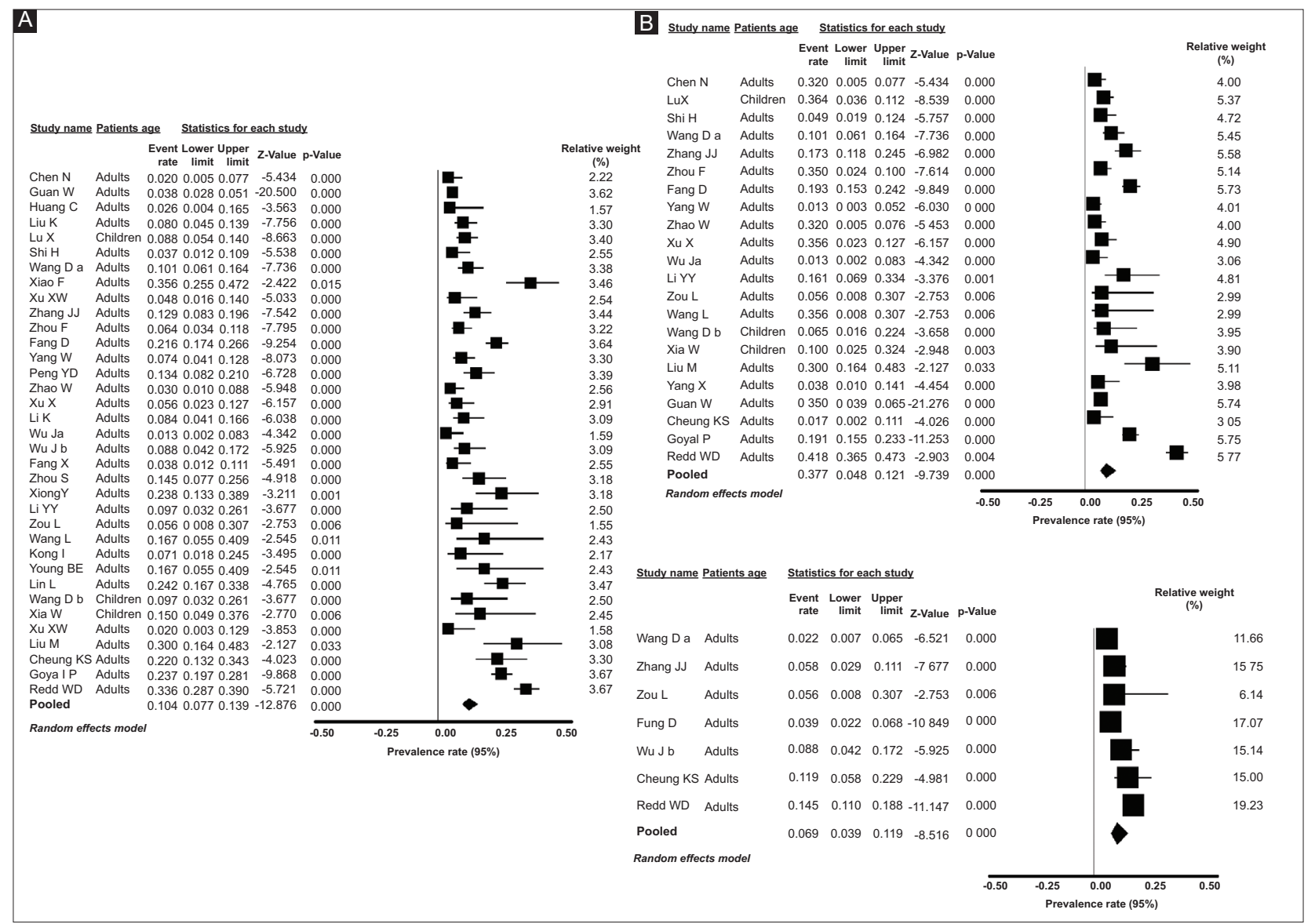

Figure 5 Forest plots showing individual and pooled prevalence ratios and 95\% confidence intervals for diarrhea (A), nausea/vomiting (B), and abdominal discomfort/pain (C)

Table 2 Subgroup analyses of prevalence of gastrointestinal symptoms in COVID-19 patients by age, disease severity and geographic region

Prevalence of all gastrointestinal symptoms: subgroup analyses

\begin{tabular}{|c|c|c|c|c|c|c|c|}
\hline \multirow[t]{2}{*}{ Subgroups / (number of studies) } & \multicolumn{3}{|c|}{$\begin{array}{l}\text { Effect size and significance (Random-effects } \\
\text { model) }\end{array}$} & \multicolumn{4}{|c|}{ Heterogeneity } \\
\hline & Prevalence $(95 \% \mathrm{CI})$ & Z-value & $\mathrm{P}$-value & Q-value & $\mathrm{d}(\mathrm{Q})$ & $\mathrm{I} 2$ & P-value \\
\hline \multicolumn{8}{|l|}{ Age } \\
\hline Adults $(n=34)$ & $0.097(0.062-0.149)$ & -8.94 & $<0.001$ & 817.7 & 33 & 95.96 & $<0.001$ \\
\hline Children $(n=3)$ & $0.096(0.063-0.143)$ & -9.77 & $<0.001$ & 0.80 & 2 & 0 & 0.673 \\
\hline \multicolumn{8}{|l|}{ COVID-19 Severity } \\
\hline Non-severe disease $(n=11)$ & $0.117(0.041-0.291)$ & -3.50 & $<0.001$ & 390.14 & 10 & 97.43 & $<0.001$ \\
\hline Severe disease $(n=11)$ & $0.166(0.66-0.36)$ & -3.05 & 0.002 & 103.92 & 10 & 90.37 & $<0.001$ \\
\hline \multicolumn{8}{|l|}{ Geographic region } \\
\hline China $(n=33)$ & $0.087(0.063-0.121)$ & 12.77 & $<0.001$ & 283,9 & 32 & 88.73 & $<0.001$ \\
\hline USA $(n=2)$ & $0.521(0.342-0.694)$ & 0.219 & 0.827 & 23.96 & 1 & 95.82 & $<0.001$ \\
\hline South Korea $(n=1)$ & $0.071(0.018-0.245)$ & & & & & & \\
\hline Singapore $(\mathrm{n}=1)$ & $0.167(0.05-0.409)$ & & & & & & \\
\hline
\end{tabular}

hours and could remain stable on plastic and stainless steel for at least $72 \mathrm{~h}$ [45]. While more studies are needed in this field, viral excretion in feces and its environmental stability would cause a favorable spread of SARS-CoV-2 among human hosts, as reported during the SARS epidemics in Hong Kong [65]. The GI involvement of COVID-19 might mean the need to 


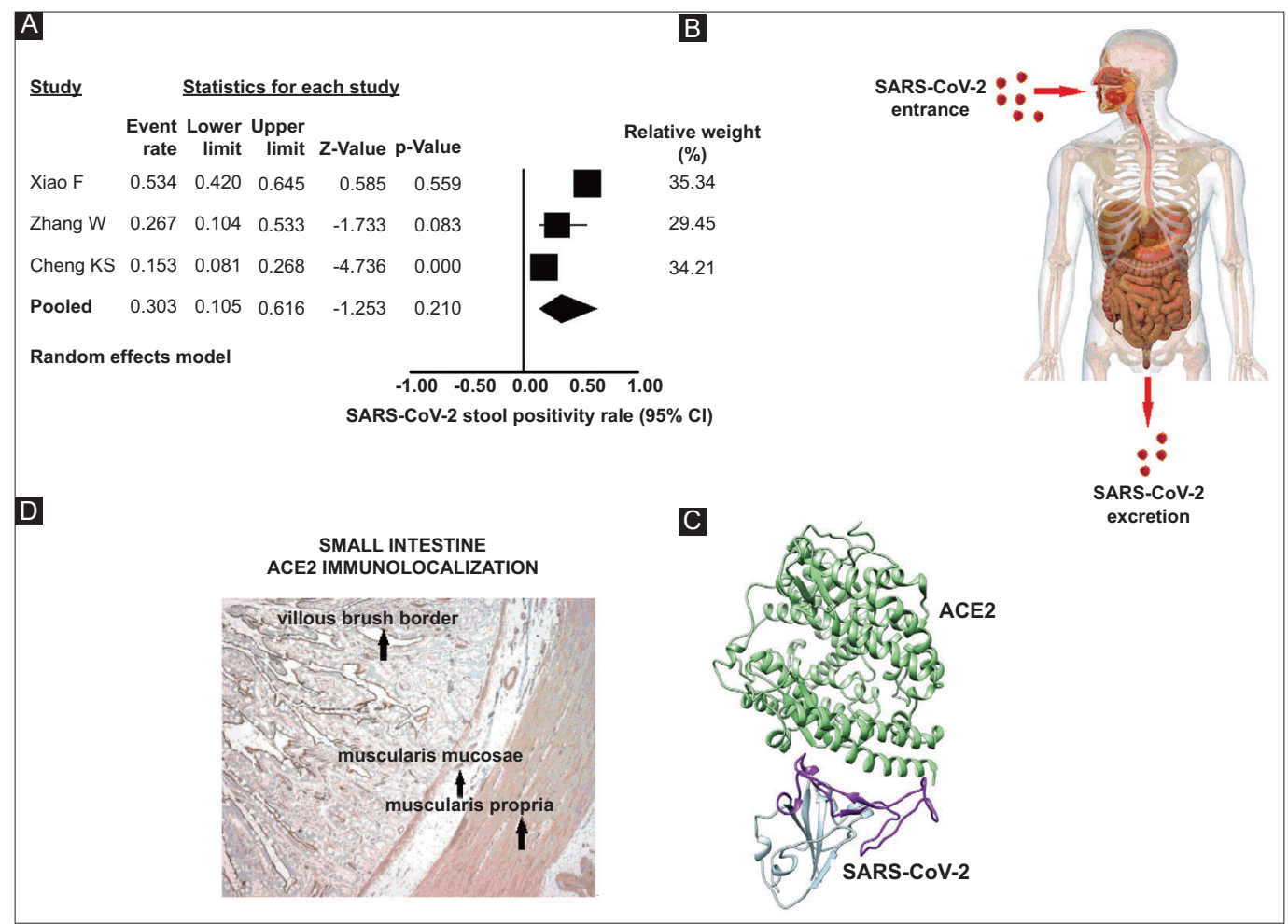

Figure 6 (A) Forest plot showing individual and pooled prevalence ratios (95\% confidence interval) of SARS-CoV-2 RNA detection in feces (B) Cartoon representation of the SARS-CoV-2 fecal route transmission. (C) Ribbon diagram depicting the SARS-CoV-2 attachment to ACE2 receptors (modified from ref. 66) (D) ACE2 small intestine immunolocalization (modified from ref. 12)

ACE2, angiotensin-converting enzyme 2

consider suitable hospital policies, such as adopting rectal swab SARS-CoV-2 testing prior to a patient's discharge [73]. Subsequently, protective policies concerning endoscopy suites should be considered [74].

Undoubtedly, the results of this meta-analysis are important and should be taken seriously into account in our battle against COVID-19. The fact that we defined the threshold of 15 patients as an inclusion criterion, as opposed to another study [26] which included numerous studies even with one patient, strengthens the results of this meta-analysis. However, some limitations should be stressed. Apart from the significant heterogeneity and publication bias observed, the main limitation is related to the fact that studies written in languages other than English were not included in this meta-analysis. Moreover, so far, the main core of relevant studies comes from China, with few studies from other countries, thus precluding a more precise estimate of the prevalence of GI manifestations in COVID-19 worldwide.

In conclusion, the digestive system is involved in COVID-19. The prevalence analysis indicates that $8.9 \%$ of patients will manifest symptoms, such as diarrhea, vomiting and abdominal pain. It seems, therefore, that the GI tract might be a target organ of SARS-CoV-2 and a potential fecal transmission route should be taken into account. This might have important implications for disease management and transmission.

\section{Summary Box}

\section{What is already known:}

- A growing body of evidence has shown that COVID-19 patients experience gastrointestinal (GI) symptoms such as diarrhea, vomiting and abdominal pain

- In some studies, SARS-CoV-2 RNA has been detected in the feces of infected patients

- Currently there is evolving research interest in this potentially lethal disease

\section{What the new findings are:}

- The pooled results of this meta-analysis showed a prevalence of $8.9 \%$, suggesting that this percentage of COVID-19 patients will manifest symptoms from the digestive system

- In $30 \%$ of the patients SARS-CoV-2 RNA was detected in feces

- The GI tract might be a target organ and potential transmission route of SARS-CoV-2, with important implications for disease management and transmission 


\section{References}

1. Huang C, Wang Y, Li X, et al. Clinical features of patients infected with 2019 novel coronavirus in Wuhan, China. Lancet 2020;395:497-506.

2. Lu R, Zhao X, Li J, et al. Genomic characterisation and epidemiology of 2019 novel coronavirus: implications for virus origins and receptor binding. Lancet 2020;395:565-574.

3. Zhou P, Yang XL, Wang XG, et al. A pneumonia outbreak associated with a new coronavirus of probable bat origin. Nature 2020;579:270-273.

4. Yi Y, Lagniton PNP, Ye S, Li E, Xu RH. COVID-19: what has been learned and to be learned about the novel coronavirus disease. Int $J$ Biol Sci 2020;16:1753-1766.

5. World Health Organization. Coronavirus disease (COVID-19) outbreak. Available from: https://www.who.int [Accessed 20 May 2020].

6. Cheng JL, Huang C, Zhang GJ, et al. [Epidemiological characteristics of novel coronavirus pneumonia in Henan]. Zhonghua Jie He He Hu Xi Za Zhi 2020;43:327-331.

7. Gu J, Han B, Wang J. COVID-19: Gastrointestinal manifestations and potential fecal-oral transmission. Gastroenterology 2020;158:1518-1519.

8. Zhang W, Du RH, Li B, et al. Molecular and serological investigation of 2019-nCoV infected patients: implication of multiple shedding routes. Emerg Microbes Infect 2020;9:386-389.

9. Xu Y, Li X, Zhu B, et al. Characteristics of pediatric SARS-CoV-2 infection and potential evidence for persistent fecal viral shedding. Nat Med 2020;26:502-505.

10. Holshue ML, DeBolt C, Lindquist S, et al; Washington State 2019-nCoV Case Investigation Team. First case of 2019 novel coronavirus in the United States. N Engl J Med 2020;382:929-936.

11. Tang A, Tong Z, Wang H, et al. Detection of novel coronavirus by RT-PCR in stool specimen from asymptomatic child, China. Emerg Infect Dis 2020;26:1337-1339.

12. Hamming I, Timens W, Bulthuis ML, Lely AT, Navis G, van Goor $\mathrm{H}$. Tissue distribution of ACE2 protein, the functional receptor for SARS coronavirus. A first step in understanding SARS pathogenesis. J Pathol 2004;203:631-637.

13. Moher D, Shamseer L, Clarke M, et al; PRISMA-P Group. Preferred reporting items for systematic review and meta-analysis protocols (PRISMA-P) 2015 statement. Syst Rev 2015;4:1.

14. Wells GA, Shea B, O'Connell D, et al. The Newcastle-Ottawa Scale (NOS) for assessing the quality if non-randomized studies in metaanalyses. Available from: http://www.ohri.ca/programs/clinical_ epidemiology/oxford.htm [Accessed 20 May 2020].

15. Rokkas T, Pistiolas D, Sechopoulos P, Robotis I, Margantinis G. The long-term impact of Helicobacter pylori eradication on gastric histology: a systematic review and meta-analysis. Helicobacter 2007;12 Suppl 2:32-38.

16. Rokkas T, Rokka A, Portincasa P. A systematic review and metaanalysis of the role of Helicobacter pylori eradication in preventing gastric cancer. Ann Gastroenterol 2017;30:414-423.

17. Mantel N, Haenszel W. Statistical aspects of the analysis of data from retrospective studies of disease. J Natl Cancer Inst 1959;22:719-748.

18. DerSimonian R, Laird N. Meta-analysis in clinical trials. Control Clin Trials 1986;7:177-188.

19. Cochran WG. The combination of estimates from different experiments. Biometrics 1954;8:101-129.

20. Higgins JP, Thompson SG, Deeks JJ, Altman DG. Measuring inconsistency in meta-analyses. BMJ 2003;327:557-560.

21. Borenstein M, Hedges LV, Higgins JPT, et al. Introduction to metaanalysis. John Wiley \& Sons, Ltd.: New York; 2009.

22. Copas JB, Shi JQ. A sensitivity analysis for publication bias in systematic reviews. Stat Methods Med Res 2001;10:251-265.
23. Begg CB, Mazumdar M. Operating characteristics of a rank correlation test for publication bias. Biometrics 1994;50:1088-1101.

24. Egger M, Davey Smith G, Schneider M, Minder C. Bias in metaanalysis detected by a simple, graphical test. BMJ 1997;315:629-634.

25. Guan WJ, Ni ZY, Hu Y, et al. Clinical characteristics of coronavirus disease 2019 in China. N Engl J Med 2020;382:1708-1720.

26. Cheung KS, Hung IF, Chan PP, et al. Gastrointestinal manifestations of SARS-CoV-2 infection and virus load in fecal samples from the Hong Kong cohort and systematic review and meta-analysis. Gastroenterology 2020 Apr 3: [Epub ahead of print]. doi: 10.1053/j. gastro.2020.03.065

27. Fang D, Ma JD, Guan JL, et al. Manifestations of digestive system in hospitalized patients with novel coronavirus pneumonia in Wuhan, China: a single-center, descriptive study. Chin J Dig 2020 40(3): [Epub ahead of print]. doi: 10.3760/cma.j.issn.0254-1432.2020.0005

28. Zhou F, Yu T, Du R, et al. Clinical course and risk factors for mortality of adult in patients with COVID-19 in Wuhan, China: a retrospective cohort study. Lancet 2020;395:1054-1062.

29. Yang W, Cao Q, Qin L, et al. Clinical characteristics and imaging manifestations of the 2019 novel coronavirus disease (COVID-19): A multi-center study in Wenzhou city, Zhejiang, China. J Infect 2020;80:388-393.

30. Zhang JJ, Dong X, Cao YY, et al. Clinical characteristics of 140 patients infected with SARS-CoV-2 in Wuhan, China. Allergy 2020 Feb 19: [Epub ahead of print]. doi: 10.1111/all.14238

31. Wang $\mathrm{D}, \mathrm{Hu} \mathrm{B}, \mathrm{Hu} \mathrm{C}$, et al. Clinical characteristics of 138 hospitalized patients with 2019 novel Coronavirus-infected pneumonia in Wuhan, China. JAMA 2020;323:1061-1069.

32. Liu K, Fang YY, Deng Y, et al. Clinical characteristics of novel coronavirus cases in tertiary hospitals in Hubei Province. Chin Med J (Engl) 2020;133:1025-1031.

33. Peng YD, Meng K, Guan HQ, et al. [Clinical characteristics and outcomes of 112 cardiovascular disease patients infected by 2019nCoV]. Zhonghua Xin Xue Guan Bing Za Zhi 2020;48:E004.

34. Zhao W, Zhong Z, Xie X, Yu Q, Liu J. Relation between chest $\mathrm{CT}$ findings and clinical conditions of coronavirus disease (COVID-19) pneumonia: a multicenter study. AJR Am J Roentgenol 2020;214:1072-1077.

35. Xu X, Yu C, Qu J, et al. Imaging and clinical features of patients with 2019 novel coronavirus SARS-CoV-2. Eur J Nucl Med Mol Imaging 2020;47:1275-1280.

36. Chen N, Zhou M, Dong X, et al. Epidemiological and clinical characteristics of 99 cases of 2019 novel coronavirus pneumonia in Wuhan, China: a descriptive study. Lancet 2020;395:507-513.

37. Liu Y, Yang Y, Zhang C, et al. Clinical and biochemical indexes from 2019-nCoV infected patients linked to viral loads and lung injury. Sci China Life Sci 2020;63:364-374.

38. Li K, Wu J, Wu F, et al. The clinical and chest CT features associated with severe and critical COVID-19 pneumonia. Invest Radiol 2020;55:327-331.

39. Shi H, Han X, Jiang N, et al. Radiological findings from 81 patients with COVID-19 pneumonia in Wuhan, China: a descriptive study. Lancet Infect Dis 2020;20:425-434.

40. Wu J, Liu J, Zhao X, et al. Clinical characteristics of imported cases of COVID-19 in Jiangsu Province: a multicenter descriptive study. Clin Infect Dis 2020 Feb 29: [Epub ahead of print]. doi: 10.1093/cid/ ciaa199

41. Wu J, Wu X, Zeng W, et al. Chest CT findings in patients with coronavirus disease 2019 and its relationship with clinical features. Invest Radiol 2020;55:257-261.

42. Fang XW, Mei Q, Yang TJ, et al. Clinical characteristics and treatment strategies of 79 patients with COVID-19. Chin Pharm Bulletin 2020;36:453-459.

43. Xiao F, Tang M, Zheng X, Liu Y, Li X, Shan H. Evidence for gastrointestinal infection of SARS-CoV-2. Gastroenterology 
2020;158:1831-1833.e3.

44. Xu XW, Wu XX, Jiang XG, et al. Clinical findings in a group of patients infected with the 2019 novel coronavirus (SARSCov-2) outside of Wuhan, China: retrospective case series. $B M J$ 2020;368:m606.

45. Zhou S, Wang Y, Zhu T, et al. CT features of Coronavirus disease 2019 (COVID-19) pneumonia in 62 patients in Wuhan, China. AJR Am J Roentgenol 2020;214:1287-1294.

46. Yang X, Yu Y, Xu J, et al. Clinical course and outcomes of critically ill patients with SARS-CoV-2 pneumonia in Wuhan, China: a single-centered, retrospective, observational study. Lancet Respir Med 2020 2020; 8:475-481.

47. Xu YH, Dong JH, An WM, et al. Clinical and computed tomographic imaging features of Novel Coronavirus Pneumonia caused by SARS-CoV-2. J Infect 2020;80:394-400.

48. Xiong Y, Sun D, Liu Y, et al. Clinical and high-resolution CT features of the COVID-19 infection: comparison of the initial and follow-up changes. Invest Radiol 2020;55:332-339.

49. Li YY, Wang WN, Lei Y, et al. [Comparison of the clinical characteristics between RNA positive and negative patients clinically diagnosed with 2019 novel coronavirus pneumonia]. Zhonghua Jie He He Hu Xi Za Zhi 2020;43:E023.

50. Liu M, He P, Liu HG, et al. [Clinical characteristics of 30 medical workers infected with new coronavirus pneumonia]. Zhonghua Jie $\mathrm{He} \mathrm{He} \mathrm{Hu} \mathrm{Xi} \mathrm{Za} \mathrm{Zhi} \mathrm{2020;43:E016.}$

51. Zou L, Ruan F, Huang M, et al. SARS-CoV-2 viral load in upper respiratory specimens of infected patients. $N$ Engl J Med 2020;382:1177-1179.

52. Wang L, Gao YH, Lou LL, et al. The clinical dynamics of 18 cases of COVID-19 outside of Wuhan, China. Eur Respir J 2020;55:2000398.

53. COVID-19 National Emergency Response Center, Epidemiology and Case Management Team, Korea Centers for Disease Control and Prevention. Early epidemiological and clinical characteristics of 28 cases of coronavirus disease in South Korea. Osong Public Health Res Perspect 2020;11:8-14.

54. Young BE, Ong SWX, Kalimuddin S, et al. Epidemiologic features and clinical course of patients infected with SARS-CoV-2 in Singapore. JAMA 2020;323:1488-1494.

55. Lu X, Zhang L, Du H, et al. SARS-CoV-2 Infection in children. $N$ Engl J Med 2020;382:1663-1665.

56. Xia W, Shao J, Guo Y, Peng X, Li Z, Hu D. Clinical and CT features in pediatric patients with COVID-19 infection: different points from adults. Pediatr Pulmonol 2020:55:1169-1174.

57. Wang D, Ju XL, Xie F, et al. [Clinical analysis of 31 cases of 2019 novel coronavirus infection in children from six provinces (autonomous region) of northern China]. Zhonghua Er Ke Za Zhi 2020;58:269-274.

58. Goyal P, Choi JJ, Pinheiro LC, et al. Clinical characteristics of covid-19 in New York City. N Engl J Med 2020 Apr 17: [Epub ahead of print]. doi: 10.1056/NEJMc2010419
59. Redd WD, Zhou JC, Hathorn KE, et al. Prevalence and characteristics of gastrointestinal symptoms in patients with SARS-CoV-2 infection in the United States: a multicenter cohort study. Gastroenterology 2020 Apr 22: [Epub ahead of print]. doi: 10.1053/j.gastro.2020.04.045

60. Lee $\mathrm{N}$, Hui $\mathrm{D}, \mathrm{Wu} \mathrm{A}$, et al. A major outbreak of severe acute respiratory syndrome in Hong Kong. N Engl J Med 2003;348:19861994.

61. Leung WK, To KF, Chan PK, et al. Enteric involvement of severe acute respiratory syndrome-associated coronavirus infection. Gastroenterology 2003;125:1011-1017.

62. Chan JF, Lau SK, To KK, Cheng VC, Woo PC, Yuen KY. Middle East respiratory syndrome coronavirus: another zoonotic betacoronavirus causing SARS-like disease. Clin Microbiol Rev 2015;28:465-522.

63. Hung IF, Cheng VC, Wu AK, et al. Viral loads in clinical specimens and SARS manifestations. Emerg Infect Dis 2004;10:1550-1557.

64. Zhou J, Li C, Zhao G, et al. Human intestinal tract serves as an alternative infection route for Middle East respiratory syndrome coronavirus. Sci Adv 2017;3:eaao4966.

65. Yu IT, Li Y, Wong TW, et al. Evidence of airborne transmission of the severe acute respiratory syndrome virus. $N$ Engl J Med 2004;350:1731-1739.

66. Tortorici MA, Veesler D. Structural insights into coronavirus entry. Adv Virus Res 2019;105:93-116.

67. Hoffmann M, Kleine-Weber H, Schroeder S, et al. SARS-CoV-2 cell entry depends on ACE2 and TMPRSS2 and is blocked by a clinically proven protease inhibitor. Cell 2020;181:271-280.e8.

68. Walls AC, Park YJ, Tortorici MA, Wall A, McGuire AT, Veesler D. Structure, function, and antigenicity of the SARS-CoV-2 spike glycoprotein. Cell 2020;181:281-292.e6.

69. Wrapp D, Wang N, Corbett KS, et al. Cryo-EM structure of the 2019-nCoV spike in the prefusion conformation. Science 2020;367:1260-1263.

70. Harmer D, Gilbert M, Borman R, Clark KL. Quantitative mRNA expression profiling of ACE 2, a novel homologue of angiotensin converting enzyme. FEBS Lett 2002;532:107-110.

71. Chan KH, Poon LL, Cheng VC, et al. Detection of SARS coronavirus in patients with suspected SARS. Emerg Infect Dis 2004;10:294-299.

72. Peiris JS, Chu CM, Cheng VC, et al; HKU/UCH SARS Study Group. Clinical progression and viral load in a community outbreak of coronavirus-associated SARS pneumonia: a prospective study. Lancet 2003;361:1767-1772.

73. Yeo C, Kaushal S, Yeo D. Enteric involvement of coronaviruses: is faecal-oral transmission of SARS-CoV-2 possible? Lancet Gastroenterol Hepatol 2020;5:335-337.

74. Repici A, Maselli R, Colombo M, et al. Coronavirus (COVID-19) outbreak: what the department of endoscopy should know. Gastrointest Endosc 2020 Mar 13: [Epub ahead of print]. doi: 10.1016/j.gie.2020.03.019 